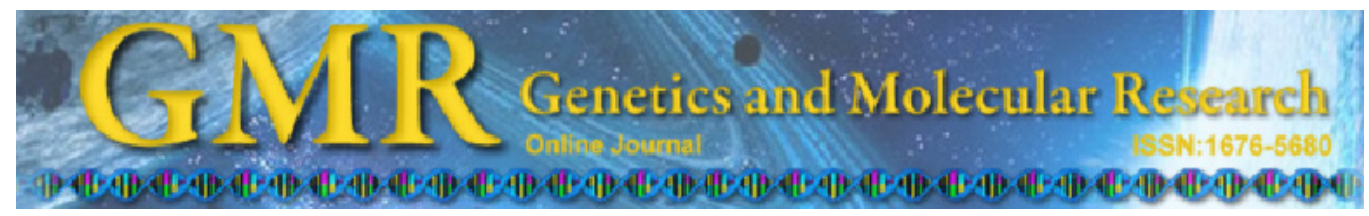

Short Communication

\title{
Multiplex PCR panel of microsatellite markers for the tambaqui, Colossoma macropomum, developed as a tool for use in conservation and broodstock management
}

\author{
I.G. Hamoy and S. Santos \\ Laboratório de Genética Humana e Médica, Instituto de Ciências Biológicas, \\ Universidade Federal do Pará, Belém, PA, Brasil \\ Corresponding author: I.G. Hamoy \\ E-mail: ighamoy@gmail.com \\ Genet. Mol. Res. 11 (1): 141-146 (2012) \\ Received September 14, 2011 \\ Accepted October 4, 2011 \\ Published January 26, 2012 \\ DOI http://dx.doi.org/10.4238/2012.January.26.1
}

\begin{abstract}
The tambaqui, Colossoma macropomum, native to Brazil, is widely used in aquaculture systems. We developed a multiplex PCR panel for this species, comprising 12 microsatellite loci. This panel was used to genotype 73 specimens collected from Juruti, a city in the Brazilian Amazon. The mean number of alleles per locus was 8.8 , the mean observed heterozygosity was 0.76 , and the combined power of discrimination and the combined power of exclusion were 0.99999999999999993 and 0.999991762 , respectively. We observed no significant deviation from Hardy-Weinberg equilibrium in this population. All amplified alleles were clearly typed, and easily interpretable results were obtained. This method will be useful for paternity analysis, population genetics and conservation studies, as well as for selective breeding programs for C. macropomum.
\end{abstract}

Key words: Colossoma macropomum; Tambaqui; Microsatellites; Multiplex panel 


\section{INTRODUCTION}

Colossoma macropomum (tambaqui), one of the most important tropical freshwater fishes of the Amazon region, is a characid found in rivers, lakes and floodplains (Marcuschi et al., 2010). This species has been considered to be overexploited since 1980 (Batista and Miguel Jr., 2003); estimates of the genetic diversity of natural populations are one of the most important tools to evaluate the population's viability (Radwan et al., 2009). C. macropomum shows a high productivity under intensive farming conditions, and this species is the most frequently cultivated fish in North Brazil (Chagas et al., 2007). In aquaculture, one of the greatest problems is the limited number of programs for selecting broodstock (Jackson et al., 2003).

Microsatellite DNA is one of the best molecular markers for broodstock management and for estimating the genetic diversity of natural populations. The codominance and high number of polymorphisms of microsatellite DNA allow for genetic differentiation between closely related populations (Na-Nakorn et al., 2010). Microsatellite markers have been developed for C. macropomum; however, a large number of microsatellites are usually necessary, which can be labor-intensive and expensive. Cost reduction can nevertheless be achieved through multiplex assays that use either the coamplification of several microsatellites in a single reaction or a mixture of products from multiple amplifications for multiplex panels (Hamoy et al., 2008; Novel et al., 2010; Skrbinšek et al., 2010; Ciofi et al., 2011).

The aim of this study was to develop and standardize a multiplex panel of 12 microsatellite markers previously described for C. macropomum that will allow future analysis of different populations.

\section{MATERIAL AND METHODS}

A total of 73 samples of $C$. macropomum were caught in the municipality of Juruti, in lower Amazon, Brazil. A sample of $2 \mathrm{~g}$ muscle tissue was collected from each individual, preserved in $95 \%$ ethanol, and stored at $4{ }^{\circ} \mathrm{C}$. Total genomic DNA was extracted from tissue digested in a proteinase K/sodium dodecyl sulfate solution; DNA was purified using the standard phenol/chloroform method, followed by precipitation with isopropanol (Sambrook and Russell, 2001). The samples were quantified using a NanoDrop ${ }^{\mathrm{TM}}$ ND-1000 spectrophotometer (Thermo Scientific).

The primers were the same as those described by Hamoy et al. (2011), except the reverse primer for microsatellite Cmacr 02 . We used a different primer for this marker because this marker overlaps the marker Cmacr $\mu 03$. The new reverse primer, which excludes the overlap with the marker Cmacr $\mu 03$ and has an annealing temperature of $60^{\circ} \mathrm{C}$, was designed using the Primer 3 program (Rozen and Skaletsky, 2000) (Table 1). The possibility of forming secondary structures between the primers was tested using the AutoDimer software (Vallone and Butler, 2004).

PCR with simultaneous amplification of 10 markers (amplification I) was standardized to a final volume of $8.0 \mu \mathrm{L}$ using 6.5 $\mu \mathrm{L}$ 2X QIAGEN Multiplex PCR Master Mix (Qiagen), $0.5 \mu \mathrm{L}$ primer mix and $1.0 \mu \mathrm{L}$ genomic DNA. The relative proportion of each primer in primer mix (made up from $100 \mu \mathrm{M}$ solutions) is given in Table 1. The reactions were optimized to amplify $20 \mathrm{ng}$ genomic DNA. The markers Cmacr $\mu 2$ (amplification II) and Cmacr $\mu 06$ (amplification III) were individually amplified, the reactions were conducted in 12 $\mu \mathrm{L}$ containing $10 \mathrm{mM}$ Tris- $\mathrm{HCl}, \mathrm{pH} 8.3,50 \mathrm{mM} \mathrm{KCl}, 1.5 \mathrm{mM} \mathrm{MgCl}_{2}, 20$ ng DNA, $0.3 \mu \mathrm{M}$ of each primer, $0.125 \mathrm{mM}$ dNTPs and $1 \mathrm{U}$ Platinum Taq DNA polymerase (Invitrogen), because these markers were not sufficiently amplified in the multiplex reaction. 


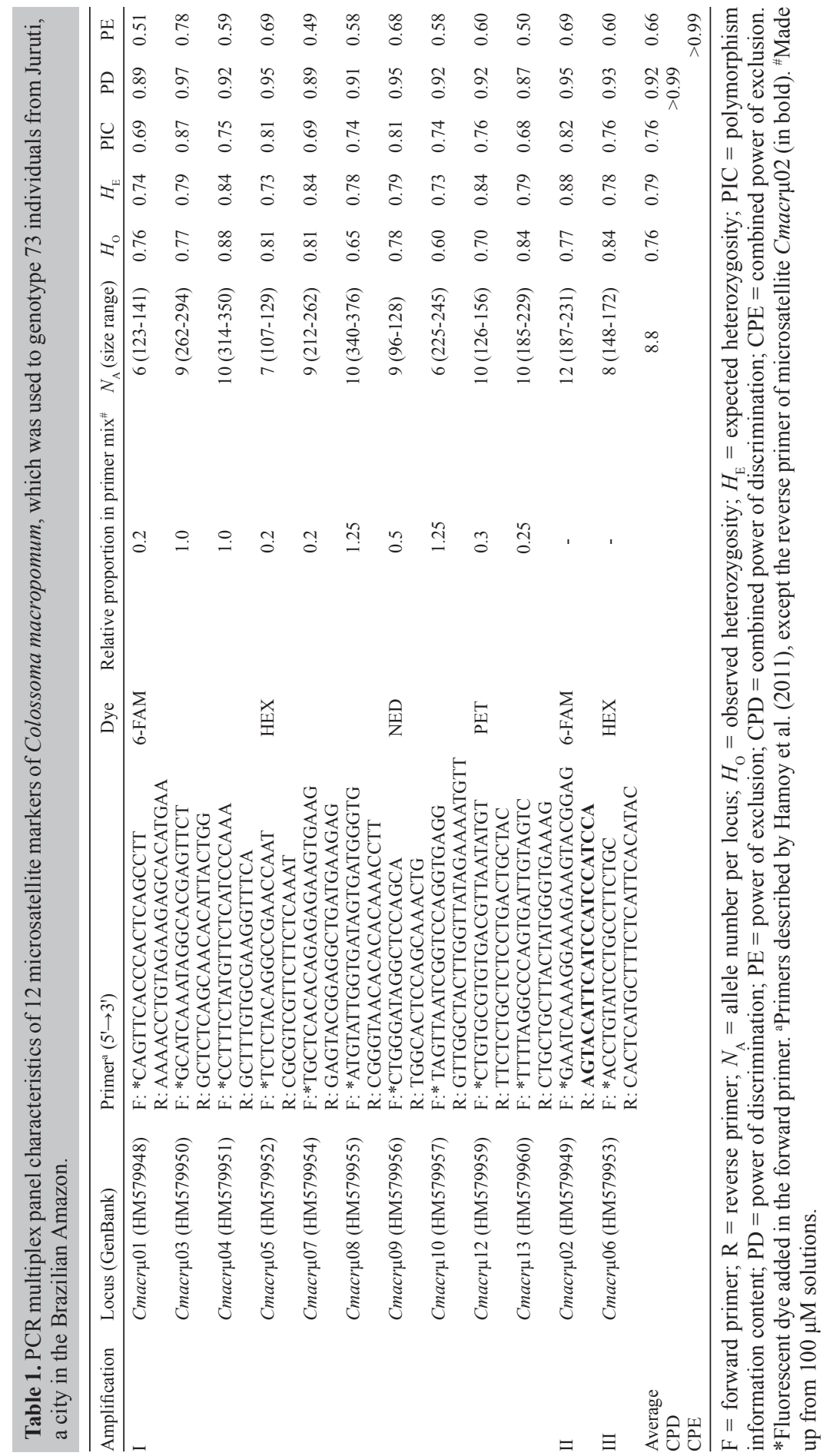


Amplification I, II and III reactions were performed in a Veriti thermocycler (Applied Biosystems). The thermocycling conditions were as follows: initial denaturation at $95^{\circ} \mathrm{C}$ for $15 \mathrm{~min}$, followed by 10 cycles at $94^{\circ} \mathrm{C}$ for $30 \mathrm{~s}, 60^{\circ} \mathrm{C}$ for $90 \mathrm{~s}$, and $72^{\circ} \mathrm{C}$ for $60 \mathrm{~s} ; 20$ cycles at $94^{\circ} \mathrm{C}$ for $30 \mathrm{~s}, 58^{\circ} \mathrm{C}$ for $90 \mathrm{~s}$, and $72^{\circ} \mathrm{C}$ for $60 \mathrm{~s}$, and a final extension at $72^{\circ} \mathrm{C}$ for $60 \mathrm{~min}$.

One microliter of amplification I, $1 \mu \mathrm{L}$ amplification II and $1 \mu \mathrm{L}$ amplification III were mixed with $8.5 \mu \mathrm{L}$ Hi-Di deionized formamide (Applied Biosystems) and $0.5 \mu \mathrm{L}$ GeneScan 500 LIZ (Applied Biosystems) as a molecular weight standard and analyzed using an ABI 3130 Genetic Analyzer (Applied Biosystems). The determination of fragment size and allele designation was done with the GeneMapper 3.7 software (Applied Biosystems) (Figure 1). After the initial genotyping, DNA samples from the most frequent alleles were sequenced to identify the correct number of repeats. The sequencing reactions were performed directly using a Big Dye Terminator v3.1 Cycle Sequencing kit ${ }^{\mathbb{B}}$ (Applied Biosystems).

The dataset was checked for genotyping errors and null alleles using Micro-Checker (Van Oosterhout et al., 2004). We analyzed the genetic variability using the allele number per locus $\left(N_{\mathrm{A}}\right)$, the observed $\left(H_{\mathrm{O}}\right)$ and expected $\left(H_{\mathrm{E}}\right)$ heterozygosities and deviation from HardyWeinberg equilibrium (HWE), using Arlequin 3.5.1.2 (Excoffier and Lischer, 2010) followed by Bonferroni's correction (Rice, 1989). The same program was used to determine the proportion of locus pairs in linkage disequilibrium (LD). We also estimated the polymorphism information content (PIC), power of discrimination (PD) and power of exclusion (PE) for all markers using the PowerStats v1.2 software (Tereba, 1999).

\section{RESULTS}

The multiplex panel contained no detected artifact peaks, and we found no indication of genotyping errors attributed to stutter bands, large allele dropout or null alleles. There was also no overlap between the microsatellite alleles (Figure 1). Consistent results were obtained in repeated analyses of randomly chosen DNA samples. Moreover, no discrepancies were observed in allele identification with either single or multiplex PCR.

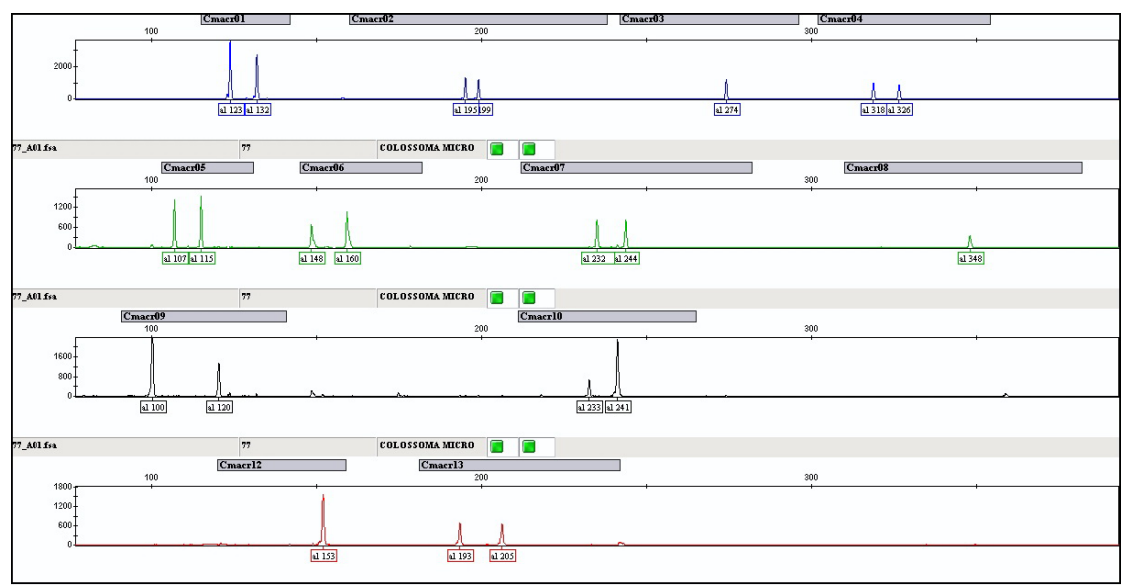

Figure 1. Multiplex PCR panel electrophoretogram for Colossoma macropomum showing the allele size range obtained using the ABI 3130 Genetic Analyzer (Applied Biosystems) and the GeneMapper 3.7 (Applied Biosystems) software. Colors were assigned to microsatellite primers labeled with 6-FAM (blue), HEX (green), NED (black), and PET (red) fluorescent dyes. 
The $N_{\mathrm{A}}$ varied from 6 to 12 , with an average of 8.8 , and $H_{\mathrm{O}}$ varied from 0.65 to 0.88 , with an average of 0.76 . No deviation from HWE was observed for the loci, and no significant LD was found between the locus pairs (Table 1). The forensic parameters investigated showed high average values: $\mathrm{PIC}=0.76, \mathrm{PD}=0.92$, and $\mathrm{PE}=0.66$. The combined power of discrimination and combined power of exclusion for the 12 microsatellites studied were 0.99999999999999993 and 0.999991762 , respectively (Table 1).

\section{DISCUSSION}

Parameters of genetic diversity, such as the average $H_{\mathrm{O}}(>70 \%)$ and the average $N_{\mathrm{A}}$ (8.8), were high and were in agreement with those described by Hamoy et al. (2011) for the same markers in a natural C. macropomum population also caught in the lower Amazon. Hamoy et al. (2011) also found an average $H_{\mathrm{O}}>70 \%$ and an average $N_{\mathrm{A}}$ of 7.0. Our results were also similar to those of other multiplex panels of microsatellite markers used to study natural populations, as reported by Olafsson et al. (2010). This high genetic variability found in our analysis also corroborates the findings of Santos et al. (2009) for 14 microsatellite markers for C. macropomum in a natural population in the lower Amazon. The power statistics of the forensic parameters was high, allowing parentage studies of $C$. macropomum. These results are similar to those with other multiplex genotyping systems of microsatellites in aquaculture, such as the ones described by Borrell et al. (2011).

The multiplex PCR method developed in this study was highly effective for the analysis of our samples, and it was less costly in terms of both time and money than scoring each marker with independent PCRs. Guichoux et al. (2011) showed that even for a moderate number of samples (100), multiplexing is an inexpensive method, 12-plex is eight times less expensive than simplex PCR.

\section{CONCLUSION}

This multiplex panel was shown to be able to quantify the genetic variability of the C. macropomum population investigated. This combination of loci affords sufficient statistical power to determine patterns of parentage and for population assignment tests. This set of multiplex assays may therefore represent an important tool for genetic analyses of natural populations and may aid in the development of aquaculture management programs for $C$. macropomum.

\section{ACKNOWLEDGMENTS}

Research supported by Conselho Nacional de Desenvolvimento Científico e Tecnológico (CNPq) and Financiadora de Estudos e Projetos (FINEP).

\section{REFERENCES}

Batista VS and Miguel P Jr (2003). Caracterização da produção pesqueira desembarcada pela pesca profissional em Manaus, Amazonas, Brasil. Acta Amaz. 33: 53-66.

Borrell YJ, Gallego V, García-Fernández C, Mazzeo I, et al. (2011). Assessment of parental contributions to fast- and slow-growing progenies in the sea bream Sparus aurata L. using a new multiplex PCR. Aquaculture 314: 58-65. 
Chagas EC, Gomes LC, Martins H Jr and Roubach R (2007). Tambaqui productivity reared in cages with different feeding rations. Cienc. Rural 37: 1109-1115.

Ciofi C, Tzika AC, Natali C, Watts PC, et al. (2011). Development of a multiplex PCR assay for fine-scale population genetic analysis of the Komodo monitor Varanus komodoensis based on 18 polymorphic microsatellite loci. Mol. Ecol. Resour. 11: 550-556.

Excoffier L and Lischer HEL (2010). Arlequin suite ver 3.5: a new series of programs to perform population genetics analyses under Linux and Windows. Mol. Ecol. Resour. 10: 564-567.

Guichoux E, Lagache L, Wagner S, Chaumeil P, et al. (2011). Current trends in microsatellite genotyping. Mol. Ecol. Resour. 11: 591-611.

Hamoy IG, Santos EJ and Santos SE (2008). Rapid and inexpensive analysis of genetic variability in Arapaima gigas by PCR multiplex panel of eight microsatellites. Genet. Mol. Res. 7: 29-32.

Hamoy IG, Cidade FW, Barbosa MS, Gonçalves EC, et al. (2011). Isolation and characterization of tri and tetranucleotide microsatellite markers for the Tambaqui (Colossoma macropomum, Serrasalmidae, Characiformes). Conserv. Genet. Resour. 3: 33-36.

Jackson TR, Martin-Robichaud DJ and Reith ME (2003). Application of DNA markers to the management of Atlantic halibut (Hippoglossus hippoglossus) broodstock. Aquaculture 220: 245-259.

Marcuschi M, Esposito TS, Machado MF, Hirata IY, et al. (2010). Purification, characterization and substrate specificity of a trypsin from the Amazonian fish tambaqui (Colossoma macropomum). Biochem. Biophys. Res. Commun. 396: 667-673.

Na-Nakorn U, Yashiro R, Wachirachaikarn A, Prakoon W, et al. (2010). Novel microsatellites for multiplex PCRs in the Humpback grouper, Cromileptes altivelis (Valenciennes, 1828), and applications for broodstock management. Aquaculture 306: 57-62.

Novel P, Porta JM, Porta J, Béjar J, et al. (2010). PCR multiplex tool with 10 microsatellites for the European seabass (Dicentrarchus labrax) - Applications in genetic differentiation of populations and parental assignment. Aquaculture 308 (Suppl 1): S34-S38.

Olafsson K, Hjorleifsdottir S, Pampoulie C, Hreggvidsson GO, et al. (2010). Novel set of multiplex assays (SalPrint15) for efficient analysis of 15 microsatellite loci of contemporary samples of the Atlantic salmon (Salmo salar). Mol. Ecol. Resour. 10: 533-537.

Radwan J, Biedrzycka A and Babik W (2009). Does reduced MHC diversity decrease viability of vertebrate populations? Biol. Cons. 3: 537-544.

Rice WR (1989). Analyzing tables of statistical tests. Evolution 43: 223-225.

Rozen S and Skaletsky HJ (2000). Primer 3 on the www for General Users and for Biologist Programmers. In: Bioinformatics Methods and Protocols: Methods in Molecular Biology (Krawetz S and Misener S, eds.). Humana Press, Totowa, 365-386.

Sambrook J and Russell D (2001). Molecular Cloning: A Laboratory Manual. 3rd edn. Cold Spring Harbor Laboratory Press, New York.

Santos MCF, Hrbek T and Farias IP (2009). Microsatellite markers for the tambaqui (Colossoma macropomum, Serrasalmidae, Characiformes), an economically important keystone species of the Amazon River floodplain. Mol. Ecol. Resour. 9: 874-876.

Skrbinšek T, Jelencic M, Waits L, Kos I, et al. (2010). Highly efficient multiplex PCR of noninvasive DNA does not require pre-amplification. Mol. Ecol. Resour. 10: 495-501.

Tereba A (1999). Tools for Analysis of Population Statistics. Profile in DNA 14-16. Free Software Distributed by the Authors at Website. Available at [http://www.promega.com/geneticidtools/]. Accessed February 10, 2011.

Vallone PM and Butler JM (2004). AutoDimer: a screening tool for primer-dimer and hairpin structures. Biotechniques 37: 226-231.

Van Oosterhout C, Hutchinson WF, Wills DPM and Shipley P (2004). Micro-Checker: software for identifying and correcting genotyping errors in microsatellite data. Mol. Ecol. Notes. 4: 535-538. 